\title{
Self-reported barriers of middle-aged and older adults entering a home-based physical activity program
}

\author{
Diana Lattimore ${ }^{1}$, Sara Wilcox ${ }^{2}$, Ruth Saunders ${ }^{2}$, Sarah Griffin ${ }^{3}$, Elizabeth Fallon ${ }^{4}$, \\ Steven Hooker ${ }^{2}$ and J. Larry Durstine ${ }^{2}$ \\ ${ }^{1}$ University of San Francisco \\ ${ }^{2}$ University of South Carolina \\ ${ }^{3}$ Clemson University \\ ${ }^{4}$ Kansas State University
}

\begin{abstract}
The purpose of this study was to assess barriers experienced by mid-older adults upon entering a homebased, telephone-delivered physical activity (PA) program and examine differences in barriers for subgroups. Methods: Three hundred eighty four participants recruited from Tennessee, California, and Illinois for the Active Choices program, which was part of Active for Life ${ }^{\circ}$, completed one face-to-face counseling session and received follow-up telephone counseling. Barriers were analyzed qualitatively and quantitatively for subgroups of mid-older adults. Results: Personal, social, and environmental themes emerged as barriers. Lack of motivation was most salient for men while health barriers were more prominent for women; however, no significant differences were found between men and women. Both whites and African Americans reported lack of motivation as the most frequent barrier to PA. Health and weather barriers were more prominent for the oldest group of older adults. Few differences were reported by PA or weight status. Conclusions: In a large sample of mid-older adults varying in age, race, gender, and health status, multiple barriers to PA were reported. Differences across subgroups may have implications for future PA interventions.
\end{abstract}

(C) 2011 Californian Journal of Health Promotion. All rights reserved.

Keywords: older adults, physical activity, obstacles, subgroups

\section{Introduction}

Physical activity plays a major role in preventing or delaying the onset of chronic diseases. Regular participation in physical activity results in significant physical and mental health benefits (American College of Sports Medicine, 1998; Cress, 2004). According to the Centers for Disease Control and Prevention, only 36.3\% of adults 65 years and older report meeting the recommended amounts of physical activity, and over $32 \%$ reported no leisure time physical activity (Centers for Disease Control and Prevention, 2003). Given the higher prevalence of physical inactivity among mid-older adults, and the well-documented benefits of physical activity participation, it is important to identify factors that influence and impede physical activity participation to help increase physically active lifestyles among middle-aged and older persons. In spite of the known benefits of regularly participating in physical activity, obstacles to adopting and/or maintaining regular physical activity exist (Schutzer \& Graves, 2004). Understanding and addressing barriers is important to effectively change behavior.

Both qualitative and quantitative studies have found that many barriers exist to adopting and maintaining physical activity with middle-aged and older adults. These barriers can be grouped into individual, environmental, and social categories. In a recent quantitative study, several barriers including lack of time and social capital (connections within social networks), transportation issues, and environmental 
concerns contributed to low levels of physical activity among adults (Zlot, 2006). Furthermore, poor health, lack of knowledge, lack of physician support or counseling, and environmental concerns were all reported as barriers to exercise in a recent review targeting older adults (Schutzer \& Graves, 2004). Additionally, health problems (e.g., arthritic pain, knee problems, and heart conditions) were mentioned as consistent barriers to physical activity among older adults (Clark, 1999a \& Conn, 1998; O'Neill \& Reid, 1991; WalcottMcQuigg \& Prohaska, 2001.). Several studies indicate that middle-aged and older adults perceive lack of time because of family responsibilities. Family responsibilities also contribute to feeling too tired to exercise (King et al., 2000; Wilcox, Richter, Henderson, Greaney, \& Ainsworth, 2002; Walcott-McQuigg \& Prohaska, 2001; Wilcox, Castro, King, Housemann, \& Brownson, 2000). Moreover, environmental concerns are prominent barriers experienced by adults, and in particular older adults. For example, cost and location of fitness facilities (Eyler et al., 1998 \& Jones \& Nies, 1996; Kinne, Patrick, \& Maher, 1999; Wilcox, Oberrecht, Bopp, Kammermann, \& McElmurray, 2005) lack of transportation (Wilcox et al., 2005), poor weather (Clark, 1999a, 1999b; Conn, 1998), lack of sidewalks (Clark, 1999a; Conn, 1998; Wilcox et al., 2005;), lack of places to sit down while out exercising (Clark, 1999a; Jones \& Nies, 1996), and safety concerns (traffic, crime, lights, and unrestrained dogs) (Clark, 1999a, 1999b; Eyler et al., 1998; Schutzer \& Graves, 2004; Wilcox et al., 2005) are all cited as barriers to participation in physical activity among older adults.

A significant gap in the current literature is that few studies have examined barriers to physical activity in subgroups of older adults. For example, while barriers of adults and older adults have been examined previously, differences in barriers among various age brackets of older adults have not. Similarly, examining barriers among those who are obese versus non-obese and those completely sedentary versus those who participate in some activity is lacking. Furthermore, barriers are typically not assessed upon entry to a program in these subgroups, and the use of qualitative research to understand barriers from the perspective of the participant is rare. Research indicates preferences of home-based physical activity programs among older adults (Atienza, 2001; Dishman, 1994; Wilcox, King, Brassington, \& Ahn, 1999), and telephonedelivery counseling for physical activity, which has shown positive results, is one common method used in home-based interventions (King, Haskell, et al., 1991; Juneau, 1987; \& Stewart, Mills, Sepsis, King, McLellan, Roitz, et al., 1997). Therefore, the purpose of this study was to qualitatively assess barriers experienced by middle-aged to older adults upon entering a home-based physical activity program and to examine differences (qualitatively and quantitatively) in barriers across demographic and health-related subgroups.

\section{Methods}

\section{Overview of Active Choices}

This paper is based on a larger project, Active for Life ${ }^{\circledR}$ (see Wilcox et. al, 2006 for more details). Active for Life is a research-to-practice study for mid-life and older adults not achieving the Centers for Disease Control and Prevention and American College of Sports Medicine (CDC-ACSM) minimum recommendation for physical activity (Pate et al., 1995). Four organizations including Blue Shield of California, Church Health Center (Memphis, TN), YMCA of Metropolitan Chicago, a collaboration between the San Mateo County Health Services (San Mateo, CA) and the City of Berkeley Health Department (Berkeley, CA) were selected as grantee sites to implement the Active Choices program model, a home-based physical activity program developed at Stanford University. Five grantee sites implemented the Active Living Every Day program model, a group-based physical activity program (Wilcox et al., 2006). This paper focuses on those who participated in the Active Choices model of the overall Active for Life program. Active Choices used a telephone delivery model implemented by a trained health educator. Individual level data were collected and used for analysis. All participants completed an informed consent to be involved in the Active Choices program and 
evaluation. Approval for the entire Active for Life project was obtained from the University of South Carolina and Texas A\&M University Institutional Review Boards.

\section{Face-to-Face Session with Health Educator}

All participants began the Active Choices program with a face-to-face meeting with a health educator. Face-to-face sessions were completed with 384 participants either individually $(59.9 \%)$ or in small groups $(40.1 \%)$ and lasted approximately 60 to 90 minutes. During this session, rapport was established between the health educator and the participant, and a discussion of participant commitment and program expectations took place. Together the health educator and participant developed an initial physical activity plan, and each participant was given tools (e.g., calendar and pedometer for tracking physical activity) to help monitor their progress. These tools were used solely for tracking progress and not examining actual physical activity levels. The health educator and participant discussed possible activity choices and optimal times and locations for activity. Both benefits and barriers to physical activity were discussed using a semistructured form that guided questions. The health educator also discussed physical activity safety and provided resources to the participant regarding local programs. The participant set personal activity goals during the face-to-face session that served as the basis for follow-up telephone calls. The purpose of each follow-up call was to assess current health status, follow up on previous goals, recommend modifications, and help the participant set new goals. At the completion of the session, the health educator and participant scheduled the first follow-up telephone call.

\section{Measures \\ Barrier Information. All barriers that arose during the face-to-face session were recorded on paper forms and entered into a Microsoft Access database by staff at the local grantee sites. Specifically, during the face-to-face session participants were asked questions in order to inquire about previous challenges or barriers with physical activity as well as potential barriers to engaging in physical activity}

participants envisioned. For example, if the participant was already engaging in some physical activity, he/she was asked to identify any barriers that currently existed. If, however, the participant had never tried to be more physically active he/she was asked to think about which barriers might pose a problem. This information was documented for each participant, recorded, and used for analyses in this paper. For the purpose of this study the term "barrier" was used to describe anything participants reported as obstacles to being physically active. A barrier is not necessarily something that keeps a person from being physically active, but something that is perceived as an obstacle to overcome in order to be physically active.

Participant Surveys. All participants enrolled in Active for Life completed a pre- and postintervention survey. For both the pre- and postintervention surveys, participants reported their date of birth, race, and gender. Participants also reported height and weight (used to compute body mass index as $\mathrm{kg} / \mathrm{m} 2$ ) and physical activity level. The Community Healthy Activities Model Program for Seniors (CHAMPS) (Stewart, Mills et al., 2001) questionnaire was used to assess physical activity. Based on this questionnaire, hours per week of moderate and vigorous intensity physical activity (MVPA) were derived (Wilcox et al., 2006). The CHAMPS questionnaire has sound psychometrics with demonstrated reliability (Harada, Chiu, King, \& Stewart, 2001), validity (Harada et al., 2001), and sensitivity to change (Stewart, 2001; Stewart, Mills et al., 2001; Stewart, Verboncoeur et al., 2001; Stewart et al., 1997).

\section{Participants}

Participants for this study were part of Active for Life (see Wilcox, et al. 2006 for more details) were enrolled in the Active Choices program during the first year of the study. Participants were recruited and screened for the program by individual grantee sites through a variety of methods including community presentations, flyers, direct mail, newspaper advertisements, and special events. Recruitment methods were tailored to reach the diverse communities. The target population was middle- 
aged to older adults 50 years of age or older who were underactive (not meeting the CDC-ACSM minimum recommendation for PA) and relatively healthy (i.e., no major contraindications to physical activity).

\section{Sample Subgroups}

Initial barriers were examined for all participants and by demographic and health-related subgroups. Specifically, age, race, gender, body mass index, and baseline physical activity were used to categorize participants into subgroups. These subgroups were chosen based on characteristics of the sample population, current gaps in the literature, and the potential influence these variables are known to have on physical activity behavior.

Age was divided into three subgroups: 50-64 years (middle-aged), 65-74 years (young-old adults), and 75 years and older (older-old adults). Due to the very small number of participants in some racial/ethnic groups, race differences were only examined for white versus Black or African American participants. Nonobese participants (BMI $<30 \mathrm{~kg} / \mathrm{m} 2$ ) were compared to obese participants (BMI > 30.0 $\mathrm{kg} / \mathrm{m} 2$ ). Baseline physical activity was divided into those who were completely sedentary and those reporting some physical activity.

\section{Qualitative Methods and Analysis}

\section{Qualitative Method}

Qualitative analyses were based on a grounded theory approach, which according to Strauss and Corbin (1990) is "theory derived from data" (Strauss, 1990). Therefore, analyses took place without preconceived thoughts or theories in mind allowing the theory to evolve from the data (Strauss, 1998). This approach allows for greater insight and deeper understanding of thoughts and feelings experienced by the participants.

Central to grounded theory is the continual process of examining the data, comparing codes and categories, and comparing emerging themes until the data have reached theoretical saturation (Strauss, 1990, 1998). Theoretical saturation is the point at which no new concepts or overall themes emerge (Strauss, 1998). This process begins with open coding, which is the progression of identifying concepts within the data (Strauss, 1998). These concepts or phenomena are categorized together to form overall themes. Thus, this process is repeated until saturation of the data occurs. In this study, existing data were used, which precluded the opportunity to continue sampling. However, with the large sample size, saturation of data was likely.

\section{Coding Procedure}

All information that arose during the face-toface session with each participant, which was recorded as "barriers" by the health educator were coded. Three individuals coded all data. All three coders initially read through the documented barriers at the face-to-face session for all participants and generated a list of topics that were then organized into a coding tree with category definitions. The first author coded all data with the two assistant coders each coding two groups (grantee sites) of participant data. Each person independently coded all notes entered in the face-to-face barriers topic field, and the pair met to discuss all codes and come to consensus. Based on independent coding there was a $69-71 \%$ initial agreement between coders and complete consensus was reached. The consensus codes for each participant were entered into N-Vivo, a computer software package designed to facilitate qualitative analyses.

Throughout the entire coding process, new codes were discussed and added to the original coding tree when appropriate. All coders were informed of any changes and received updated coding trees and category definitions. Previously coded material was recoded to reflect changes. Following the completion of all coding, the three coders read through all coded text and met to discuss all categories and overall themes. The final emerging themes, sub-themes and categories were used to describe the barriers that existed for all participants and subgroups of the population.

\section{Quantitative Methods and Analysis}

Chi square analyses were used to quantitatively assess whether the types of barriers differed 
according to the sample subgroups described earlier. These analyses were conducted using SAS statistical software. Although three levels (theme, sub-theme, and category) of analysis were used to organize the barrier types for qualitative analyses, only the sub-theme (for personal barriers) or overall theme (for environmental and social barriers) was used for quantitative analyses. Barrier types were coded for each participant as absent (coded 0) or present (coded 1). For example, participants reporting a barrier in any of the time categories (work constraints, family constraints, or general lack of time) received a code of 1 for time barriers (sub-theme). If the participant did not report barriers for any of the time categories, he/she received a code of 0 for time barriers. Because substantially fewer participants reported environmental or social barriers upon entry into the program these sub-themes were collapsed into the overall theme for quantitative analyses. Themes, sub-themes, and categories are described qualitatively for subgroups.

\section{Results}

\section{Characteristics of the participants}

A total of 384 participants were recruited into Active Choices during the first year of Active for Life and completed pre-intervention surveys. The participants were primarily female $(78.3 \%)$ and over half were white $(57.8 \%)$. Black or African Americans made up $32.4 \%$ of the sample. Participants included adults 50-64 years (45\%), 65-74 years of age (35.2\%), and 75 years or older $(19.8 \%)$. Over half of the sample was normal weight or overweight, but $46.4 \%$ were obese. At the start of the program $61.7 \%$ of the participants reported some physical activity, but $38.3 \%$ were completely sedentary.

\section{Qualitative Findings}

Most barriers reported upon entry into Active Choices fell into one of three broad themes: personal, environmental and social barriers. Health concerns, time constraints, lacking motivation, and previous exercise experience were the sub-themes for personal barriers with categories emerging from the sub-themes (see
Table 1). Under both the environmental and social barriers sub-themes such as weather or lack of an exercise partner emerged. Table 1 lists all the themes, sub-themes, and categories, as well as representative examples that emerged for the entire sample. In the table, the total number of grantee sites that had one or more participants who described a barrier in a given sub-theme or category is reported. Also, the total number of participants across sites describing that given barrier is reported.

\section{Sample subgroup analyses}

\section{Gender differences}

As shown in Table 2, lack of motivation was the most frequently described barrier for men (33\%) and health was most prominent for women $(30 \%)$. However, quantitative analyses revealed no significant gender differences for personal, environmental, or social barriers ( $p$ values > $.05)$. Both men and women described similar motivational and health barriers to physical activity. Both men and women frequently reported general lack of time as a barrier to physical activity; however, there were some differences in the kinds of time barriers described. Men described time management issues as well as doctor appointments, whereas women described babysitting, working late (odd) shifts, exercise class schedule conflicting with other responsibilities, and in general having a "busy life."

Although relatively infrequent for both men and women, men reported very few social barriers, and lack of an exercise partner was not reported as a barrier by any man.

\section{Racial Differences}

Table 2 shows the most frequent barriers for white mid-older adults were health $(36 \%)$ and lack of motivation (31\%). For instance, arthritis was one health barrier commonly mentioned as well as recovering from broken bones and overcoming previous surgeries. Similarly, African American's reported lack of motivation as the most frequent barrier (29\%). However, in 
Table 1

Physical activity barriers (number of sites and percentage of participants across all sites) reported at the face-to-face session

\begin{tabular}{lccc}
\hline $\begin{array}{l}\text { Key Themes, sub-themes and } \\
\text { categories }\end{array}$ & $\begin{array}{c}\text { \% } \\
(\text { sites })\end{array}$ & $\begin{array}{c}\text { participant } \\
(N=4)\end{array}$ & $(N=384)$ \\
\hline
\end{tabular}

\section{Personal Barriers}

Health

428

- Has Rheumatoid Arthritis and makes it difficult to exercise

- Has become generally slower getting around and balance and mobility aren't what they used to be

- Pain due to arthritis; back pain

\section{Time}

- Work constraints

- Family constraints

- General lack of time

4

4

- Lack of interest

4

4

- Lack of energy
3

4

$9 \quad \cdot$ Working a lot of hours

-Work schedule is inconsistent - and takes advantage of overtime hours when available - Lawyer for 40 years, but owns his own practice and is on boards of many community organizations that require his early mornings at times

$13 \cdot$ Limited time available (taking care of wife)

- Taking care of elderly, sick mother and grandchildren

- Too busy with family responsibilities

23 - Finding the time to exercise Doctors appointments

- Time management, scheduling his exercise into his life, and juggling work, school, and family life

\begin{tabular}{|c|c|c|c|}
\hline $\begin{array}{l}\text { Motivation } \\
\text { - Lack of interest }\end{array}$ & 4 & 5 & $\begin{array}{l}\text { - Bored with activities } \\
\text { - She has a small fitness facility in her building but doesn't like to walk on the treadmill or use } \\
\text { the stationary bike, she gets bored } \\
\text { - Has not been interested in cardiovascular or strength training exercise }\end{array}$ \\
\hline - Lack of motivation & 4 & 30 & $\begin{array}{l}\text { - Lack of motivation } \\
\text { - Change is too slow }\end{array}$ \\
\hline - Lack of energy & 4 & 11 & $\begin{array}{l}\text { - Still working so she is worn out after work } \\
\text { - Lack of endurance, exhaustion } \\
\text { - Tired or low on energy }\end{array}$ \\
\hline $\begin{array}{l}\text { Previous Exercise Experience } \\
\text { - Lack of exercise } \\
\text { knowledge or experience }\end{array}$ & 3 & 3 & $\begin{array}{l}\text { - Never did it as a child } \\
\text { - Doesn't feel like she knows enough about how to exercise and eat correctly }\end{array}$ \\
\hline $\begin{array}{l}\text { - Negative exercise } \\
\text { perceptions or experience }\end{array}$ & 3 & 4 & $\begin{array}{l}\text { - Sweating and having to go back to work } \\
\text { - Group exercise classes that are too advanced in fitness and too technical } \\
\text { - Embarrassed by what she cannot do well }\end{array}$ \\
\hline $\begin{array}{l}\text { Environmental Barriers } \\
\text { - Weather }\end{array}$ & 4 & 15 & $\begin{array}{l}\text { - In wet weather hard to get out } \\
\text { - Hot weather } \\
\text { - Weather, especially cold weather and snow/ice are barriers }\end{array}$ \\
\hline - Transportation and safety & 4 & $<\mathbf{1}$ & $\begin{array}{l}\text { - Many barriers, she has a car that doesn't work and can't get out - is unsure of taking bus to } \\
\text { go places } \\
\text { - A little worried about safety in neighborhood }\end{array}$ \\
\hline - Accessibility concerns & 4 & $<\mathbf{1}$ & $\begin{array}{l}\text { - Does not walk in neighborhood - because she lives in the hills - so hard } \\
\text { - Does not have a job so can't afford a gym membership } \\
\text { - Not belonging to a health club or having access to cardiovascular machines or weight } \\
\text { machines }\end{array}$ \\
\hline $\begin{array}{l}\text { Social Barriers } \\
\text { - Lack of social support }\end{array}$ & 2 & 2 & - Little support from spouse \\
\hline - Lack of exercise partner & 3 & 2 & -Would like someone to walk with \\
\hline $\begin{array}{l}\text { - Lack of accountability } \\
\text { person }\end{array}$ & 3 & 1 & $\begin{array}{l}\text { - Needs to set a plan, stick to it and know someone will hold her accountable to her goals } \\
\text { - Big barrier is not having someone/something to answer to if she doesn't do it }\end{array}$ \\
\hline No Barriers & 4 & $<1$ & \\
\hline
\end{tabular}

Note: percentages for each theme do not equal 100\% because participants could discuss several barriers, both across themes or within a theme. 
contrast, health was not as frequently reported as a barrier to physical activity by African American participants $(17 \%)$, and this race difference was statistically significant, $\chi^{2}(1$, $\mathrm{N}=342)=4.32,(\mathrm{p}<.04)$. No other differences in personal barriers were statistically significant $(p>.05)$, although previous exercise experience approached significance $(\mathrm{p}=.06)$. Differences were also not evident for environmental barriers $(\mathrm{p}>.05)$.

A significant difference existed for social barriers between white and African American participants, $\chi^{2}(1, \mathrm{~N}=342)=4.89, \mathrm{p}<.027$, with more whites $(7 \%)$ reporting social barriers than African Americans (2\%). In particular, white participants highlighted having to work out alone and not having any support as barriers to physical activity participation.

\section{Age differences}

Age differences in barriers are shown in Table 2. Significant age differences were found for all personal barrier sub-themes, but not for the themes of environmental or social barriers $(p$ values $>.05$ ).

Middle-aged (50-64) adults reported lack of motivation as the most frequent barrier to physical activity (35\%), and this barrier was more commonly reported by this age group, $\chi^{2}$ $(2, \mathrm{~N}=384)=12.34,(\mathrm{p}<.002)$. In contrast, both the young-old (65-74) and the older-old participants $(75+)$ reported health as the most frequent barrier (36\% and $41 \%$ respectively), and this difference relative to the middle-aged participants was statistically significant, $\chi^{2}(2$, $\mathrm{N}=384)=11.14(\mathrm{p}<.003)$. Although not always the most frequent barrier, health was a commonly reported barrier for all age groups, but differences arose in types of health barriers between age groups. Middle-aged adults described being overweight, having previous injuries/surgeries, or temporary health setbacks (e.g., kidney stones). In contrast, older participants described health barriers such as heart problems, vision limitations, muscular issues, and arthritis. The oldest group (75+), described balance and mobility limitations due to changes that had occurred over time.

Lack of time was frequently reported for all age groups, although the middle-aged (50-64) and young-old adults (65-74) were significantly more likely to report this barrier, $\chi^{2}(2, \mathrm{~N}=384)$ $=9.18,(\mathrm{p}<.01)$. While all groups described lacking time management skills or needing to find time to exercise, the middle-aged participants also described varying work schedules that created barriers to physical activity participation as well as other responsibilities and activities. Although not as frequently reported, middle-aged older adults were significantly more likely to report previous unpleasant exercise experiences as a barrier as compared to the young-old and older-old adults, $\chi^{2}(2, \mathrm{~N}=384)=6.23,(\mathrm{p}<.04)$. Middle-aged participants described past experiences of feeling stupid in class, previous discomfort walking outside around dust, wind, and stoplights, and being afraid of water, which limited enjoyment of water classes.

\section{Health related subgroup differences}

Differences in barriers by baseline physical activity level and body mass index are shown in Table 3. The quantitative analyses revealed that baseline physical activity was unrelated to personal, environmental, or social barriers ( $p$ values $>.05)$. Participants reporting some physical activity reported lack of motivation as the most frequent barrier to physical activity (28\%) followed by health $(25 \%)$ and general lack of time (23\%). Sedentary participants reported health as the most frequent barrier (34\%) followed by lack of motivation (33\%) and general lack of time (20\%).

Non-obese participants reported lack of motivation as the most frequent barrier (30\%), with general time (27\%) and health barriers $(24 \%)$ as other frequently reported barriers. In contrast, obese participants reported health as the most frequent barrier (33\%) followed by lack of motivation $(28 \%)$, time, and weather (both 16\%) (see Table 3). Non-obese participants were 
Table 2

Percentage of participants reporting personal, social, and environmental barriers to physical activity, by demographic characteristics

\begin{tabular}{|c|c|c|c|c|c|c|c|}
\hline \multirow[t]{2}{*}{ Key themes, sub-themes, and categories } & \multicolumn{2}{|c|}{$\begin{array}{c}\text { Gender } \\
\% \text { participants }\end{array}$} & \multicolumn{2}{|c|}{$\begin{array}{c}\text { Race } \\
\% \text { participants }\end{array}$} & \multicolumn{3}{|c|}{$\begin{array}{c}\text { Age } \\
\% \text { participants }\end{array}$} \\
\hline & $\begin{array}{l}\text { Male } \\
(\mathrm{n}=83)\end{array}$ & $\begin{array}{l}\text { Female } \\
(\mathrm{n}=300)\end{array}$ & $\begin{array}{c}\text { White } \\
(\mathrm{n}=221)\end{array}$ & $\begin{array}{c}\text { Black } \\
(\mathrm{n}=121)\end{array}$ & $\begin{array}{c}50-64 \\
(n=173)\end{array}$ & $\begin{array}{c}65-74 \\
(n=135)\end{array}$ & $\begin{array}{c}75+ \\
(n=76)\end{array}$ \\
\hline \multicolumn{8}{|l|}{ Personal Barriers } \\
\hline Health $* \dagger$ & 22.8 & 33.3 & 35.7 & 24.8 & 22.5 & 36.3 & 40.7 \\
\hline Time $\uparrow$ & 38.5 & 35.7 & 35.3 & 37.2 & 41.0 & 38.5 & 21.0 \\
\hline - Work Constraints & 14.5 & 8.0 & 11.3 & 2.4 & 13.8 & 7.4 & 2.6 \\
\hline - Family Constraints & 8.4 & 14.0 & 10.4 & 15.7 & 15.0 & 13.3 & 6.5 \\
\hline - General lack of time & 22.9 & 22.0 & 21.7 & 25.6 & 23.7 & 24.4 & 14.4 \\
\hline Motivation $\gamma$ & 40.9 & 40.0 & 41.2 & 42.1 & 48.5 & 37.7 & 25.0 \\
\hline - Lack of interest & 3.6 & 5.0 & 4.5 & 5.7 & 6.3 & 4.4 & 1.3 \\
\hline - Lack of motivation & 32.5 & 28.6 & 31.2 & 28.9 & 34.7 & 31.9 & 14.4 \\
\hline - Lack of energy & 6.0 & 12.0 & 7.6 & 20.6 & 13.8 & 6.6 & 10.5 \\
\hline Previous Exercise Experience $\nrightarrow$ & 7.2 & 8.0 & 9.9 & 4.1 & 11.6 & 5.2 & 3.9 \\
\hline - Lack of exercise knowledge or experience & 3.6 & 3.0 & 4.0 & .8 & 5.2 & 1.7 & 1.3 \\
\hline - Negative exercise perceptions or experience & 3.6 & 4.0 & 6.3 & .8 & 5.2 & 2.9 & 2.6 \\
\hline Environmental Barriers & 19.2 & 23.6 & 20.8 & 26.4 & 26.0 & 20.0 & 19.7 \\
\hline Weather & 13.3 & 15.0 & 13.1 & 16.5 & 13.3 & 14.1 & 18.4 \\
\hline Transportation and Safety & 4.8 & 3.3 & 3.2 & 4.9 & 4.6 & 2.9 & 2.6 \\
\hline - Accessibility concerns & 2.4 & 7.3 & 6.3 & 7.4 & 9.8 & 3.7 & 2.6 \\
\hline Social Barriers * & 3.6 & 5.0 & 6.7 & 1.7 & 4.6 & 5.2 & 3.9 \\
\hline Lack of social support & 1.2 & 1.6 & 2.2 & 0 & 2.3 & .7 & 1.3 \\
\hline Lack of exercise partner & 0 & 2.3 & 2.7 & .8 & 1.1 & 3.0 & 1.3 \\
\hline Lack of accountability person & 2.4 & 1.0 & 1.8 & .8 & 1.1 & 1.5 & 1.3 \\
\hline
\end{tabular}

Note: $*$ denotes statistically significant race difference $(\mathrm{p}<.05)$. $\dagger$ denotes statistically significant age difference $(\mathrm{p}<.05)$.

Percentages do not equal $100 \%$ because participants could discuss several barriers, both across themes or within a theme.

more likely than obese participants to report time barriers, $\chi^{2}(1, \mathrm{~N}=373)=4.31,(\mathrm{p}<.04)$, and social barriers, $\chi^{2}(1, \mathrm{~N}=373)=5.16,(\mathrm{p}<$ $.02)$. For example, some time barriers that were reported by non-obese participants included family obligations and responsibilities (e.g., caring for family members or visiting family members) and work schedules. Furthermore, social barriers included not having anyone to walk with and also not having anyone to be accountable to when activity is skipped. No other themes or sub-themes differed by obesity status. Many similarities existed in the types of motivation, time, and health barriers that were reported; however, some qualitative differences were observed for health barriers. Obese participants described being overweight (both currently and for life) as a barrier to physical activity. Obese participants also described health issues such as arthritis, fibromyalgia, muscular degeneration, heart conditions, and surgeries. In comparison, non-obese participants described mobility limitations, chronic fatigue, broken bones, illness, osteoarthritis, hypertension, and vision limitations as barriers to physical activity. 
Table 3

Percentage of participants reporting personal, social, and environmental barriers to physical activity, by health-related variables

\begin{tabular}{|c|c|c|c|c|}
\hline \multirow[t]{2}{*}{$\begin{array}{l}\text { Key themes, sub-themes, and } \\
\text { categories }\end{array}$} & \multicolumn{2}{|c|}{$\begin{array}{l}\text { Physical Activity } \\
\text { (\% participants) }\end{array}$} & \multicolumn{2}{|c|}{$\begin{array}{c}\text { BMI } \\
\text { (\% participants) }\end{array}$} \\
\hline & $\begin{array}{l}\text { Some Activity } \\
(\mathrm{n}=272)\end{array}$ & $\begin{array}{l}\text { Sedentary } \\
(\mathrm{n}=112)\end{array}$ & $\begin{array}{l}\text { Not Obese } \\
(\mathrm{n}=200)\end{array}$ & $\begin{array}{c}\text { Obese } \\
(\mathrm{n}=173)\end{array}$ \\
\hline \multicolumn{5}{|l|}{ Personal Barriers } \\
\hline Health & 29.0 & 35.7 & 30.0 & 32.3 \\
\hline Time $\dagger$ & 38.2 & 31.3 & 41.0 & 30.6 \\
\hline - Work Constraints & 10.3 & 7.1 & 11.5 & 7.5 \\
\hline - Family Constraints & 14.3 & 8.9 & 10.5 & 15.0 \\
\hline - General lack of time & 23.2 & 19.6 & 27.0 & 13.3 \\
\hline Motivation & 39.3 & 41.9 & 38.0 & 41.6 \\
\hline - Lack of interest & 5.1 & 3.5 & 4.0 & 5.7 \\
\hline - Lack of motivation & 27.9 & 33.0 & 30.0 & 28.3 \\
\hline - Lack of energy & 10.6 & 11.6 & 7.0 & 15.0 \\
\hline Previous Exercise Experience & 7.3 & 8.9 & 6.5 & 9.8 \\
\hline $\begin{array}{l}\text { - Lack of exercise knowledge or } \\
\text { experience }\end{array}$ & 4.0 & 1.8 & 2.5 & 4.6 \\
\hline $\begin{array}{l}\text { - Negative exercise perceptions or } \\
\text { experience }\end{array}$ & 3.3 & 5.4 & 4.0 & 4.0 \\
\hline Environmental Barriers & 20.9 & 26.8 & 22.0 & 24.8 \\
\hline Weather & 14.3 & 15.1 & 14.5 & 15.6 \\
\hline Transportation and safety & 3.3 & 4.5 & 4.0 & 3.4 \\
\hline - Accessibility concerns & 5.5 & 8.0 & 5.5 & 7.5 \\
\hline Social Barriers $\dagger$ & 5.1 & 4.5 & 7.5 & 2.3 \\
\hline Lack of social support & 1.1 & 2.7 & 2.0 & 1.2 \\
\hline Lack of exercise partner & 2.2 & .9 & 3.0 & 6 \\
\hline Lack of accountability person & 1.4 & .9 & 2.0 & 6 \\
\hline
\end{tabular}

Note: $\uparrow$ denotes a statistically significant difference $(\mathrm{p}<.05)$ between weight status groups. Percentages do not equal $100 \%$ because participants could discuss several barriers, both across themes or within a theme.

\section{Discussion}

The findings of this study indicate there are multiple personal, environmental, and social barriers that middle-aged and older adults experience when beginning to adopt physically active lifestyles. Also, the examination of barriers across various subgroups of middle aged-to-older adults is understudied, but necessary.

While there were some noteworthy differences between subgroups, the primary barriers for the entire sample of mid-older adults entering a physical activity program included health problems, lack of motivation, general lack of 
time, and weather. These barriers are consistent with previous studies of older adults (Clark, 1999a, 1999b; Conn, 1998 \& O'Neill \& Reid, 1991; King et al., 2000; Wilcox et al., 2002; Walcott-McQuigg \& Prohaska, 2001; Wilcox et al., 2000;). Contrary to previous findings, lack of social support was not frequently mentioned by participants in this study; however, it was reported more frequently by white participants. Previous research indicates that physician support is a significant indicator of physical activity adoption among white men and women (Macera, 1991); therefore, if advice from physicians was lacking or if participants were unsure of physician support this may have contributed to feelings of lack of support from this group. Furthermore, these findings may be a result of differences within the family structure between the two races. Finally, it is important to remember that barriers in this study were assessed upon entry into a physical activity program. Social support may be more important in maintaining a physically active lifestyle. This notion is consistent with the Transtheoretical Model (Prochaska, 1979), which theorizes that helping relationships are more important in later stages of change, when individuals are actually making behavioral change, rather than in earlier stages of change.

African American participants reported a lack of energy more frequently than health barriers. Several factors such as caretaking and general mindset may contribute to feelings of low energy and being too tired to add physical activity into daily lifestyles (Wilcox et al., 2002). Furthermore, studies indicate that middleaged and older adults perceive lack of time due to family obligations and responsibilities of taking care of children and grandchildren, which are prominent in the African American culture, and these barriers also contribute to feeling too tired for physical activity (King et al., 2000; Walcott-McQuigg \& Prohaska, 2001; Wilcox et al., 2000; Wilcox et al., 2002). Physical activity interventions need to emphasize increased energy as a positive outcome of physical activity. Also, physical activity interventions targeting African American participants should incorporate opportunities to be physically active with the entire family or as part of other family obligations (i.e., walking around the soccer field while grandchildren are at soccer practice). It may also be helpful to discuss the importance of scheduling physical activity in the morning before energy levels decrease and become a barrier.

Participants in the oldest age group (75+ years) reported weather as a more frequent barrier than in other subgroups; however, weather was consistently reported as one of the top five most frequent barriers by most subgroups. Weather conditions should be considered when designing interventions for mid-older adults, and convenient and affordable indoor physical activity options should be included. Physical activities that can be done indoors and at home appear to be a viable solution based on research supporting the notion that many older adults prefer exercising at home compared to a supervised, group-based environment (Atienza, 2001; Dishman, 1994; Wilcox et al., 1999).

Another focus of interest was differences among the three age groups of middle aged-older adults because limited information is available on those subgroups. Health and weather barriers were more salient for those 75 years of age and older as compared to the younger older adults. The percentage who reported health barriers increased as the age group increased. This finding is not surprising as chronic disease and disability increase with age (Centers for Disease Control and Prevention, 2004). The middle-aged older adults and the young-old older adults both reported lack of time as a more salient barrier than the oldest group. This finding is not surprising given that many in the younger age groups are still working and/or caring for others (children, spouses). This may also contribute to the lack of motivation that was reported in this group.

Non-obese participants reported more social barriers as compared to obese participants. This indicates support and/or exercise partners may be more readily available upon entering a physical activity program for obese individuals. Although social support may be most important for maintaining physical activity, it may also be what helps obese individuals in particular to 
initiate joining an activity program. Interestingly, participants reporting some activity and those categorized as sedentary all reported lack of motivation, general lack of time, and health problems as the top three barriers upon entering a physical activity program. This finding indicates that more active mid-to older adults have found ways to overcome these barriers, whereas completely sedentary mid-to older adults have not. This finding highlights the importance of building self-regulation skills such as goal setting, tracking activity, and using rewards along with increasing self-efficacy to help enable this population to use problem solving in order to overcome their obstacles to physical activity. Previous studies have shown that incorporating behavioral strategies such as self-regulation resulted in more effective interventions for increasing physical activity (Brawley, Rejeski, \& King, 2003).

\section{Study Limitations}

The following limitations should be considered when interpreting the results of this study. First, the health educators at the sites collected data from each of their participants during the faceto-face session and entered this information into a Microsoft Access database. Thus, the quality of these data relies on the thoroughness of each health educator, which could have varied across sites and health educators. Although all health educators were trained by Active Choices program developers, and assessment of barriers was a consistent part of the protocol, not having a standard approach (i.e., no specific probes) for assessing barriers is a second limitation to this study. Hence, health educators may have discussed barriers differently and may have used different probes to assess barriers. However, by not using a structured measure to assess barriers, participants may raise barriers that perhaps would not have been assessed with a standard instrument or questionnaire.

Another limitation to this study is that the data used were very brief in nature (short phrases), not allowing for more in-depth analysis. The health educator entered phrases from participants into the Access database; thus, they were not verbatim text that is typical in focus groups and in-depth interviews. Focus groups or in-depth interviewing allow the researcher to probe for further explanation in order to obtain more specific information leading to a deeper understanding of the participant's perceptions and experiences. We were unable to use this approach in the study.

\section{Conclusions and Contributions of Study}

This study assessed barriers to physical activity experienced by a large sample of middle-aged to older adults, and subgroups within this population upon entry into a physical activity program. The assessment of subgroups of midolder adults expands existing knowledge as few studies have addressed these subgroup differences. The results of this study reinforce the message that unique barriers exist within diverse populations of middle-aged and older adults, and that more individualized approaches may be more effective to address them.

Participants were not given a list of potential barriers; therefore, those mentioned are exclusively perceptions from the participants and are likely to be those most salient or relevant. The knowledge gained through this analysis can be used in the future to help develop interventions that address barriers experienced by subgroups of older adults. Moreover, this information can be used in developing quantitative barrier scales for subgroups of older adults.

\section{Acknowledgments}

The authors would like to acknowledge Shanikwha Jones for her data coding work for this publication. We also would like to thank the staff and the many participants at the four Active Choices sites for their valuable contributions to this study.

\section{References}

American College of Sports Medicine. (1998). American College of Sports Medicine Position Stand. Exercise and physical activity for older adults. Medicine \& Science in Sports \& Exercise, 30(6), 992-1008. 
Lattimore, D., Wilcox, S., Saunders, R. , Griffin ,S., Fallon, E., Hooker, S. \& Durstine, J.L. / Californian Journal of Health Promotion 2011, Volume 9, Issue 2, 15-28

Atienza, A. A. (2001). Home-based physical activity programs for middle-aged and older adults: summary of empirical research. Journal of Aging and Physical Activity, 9(Supplement), S38-58.

Brawley, L. R., Rejeski, W. J., \& King, A. C. (2003). Promoting physical activity for older adults: the challenges for changing behavior. American Journal of Preventive Medicine, 25(3 Suppl 2), 172183.

Centers for Disease Control and Prevention. (2003). Behavioral Risk Factor Surveillance System Survey Data, U.S. Department of Health and Human Services. Center for Disease Control and Prevention: Atlanta, Georgia.

Centers for Disease Control and Prevention. (2004). The State of Aging and Health in America 2004. Retrieved May 9, 2005, from http://www.cdc.gov/aging/pdf/State_of_Aging_and_Health_in_America_2004.pdf

Clark, D. O. (1999a). Identifying psychological, physiological, and environmental barriers and facilitators to exercise among older low income adults. Journal of Clinical Geropsychology, 5(1), 51-62.

Clark, D. O. (1999b). Physical activity and its correlates among urban primary care patients aged 55 years or older. Journal of Gerontology, 54(1), S41-48.

Conn, V. S. (1998). Older women's beliefs about physical activity. Public Health Nursing, 15(5), 370378.

Cress, M. E., Buchner, D.M., et al. (2004). Physical activity programs and behavior counseling in older adult populations. Medicine \& Science in Sports \& Exercise, 36(11), 1997-2003.

Dishman, R. K. (1994). Motivating older adults to exercise. Southern Medical Journal, 87(5), S79-82.

Eyler, A. A., Baker, E., Cromer, L., King, A. C., Brownson, R. C., \& Donatelle, R. J. (1998). Physical activity and minority women: a qualitative study. Health Education \& Behavior, 25(5), 640-652.

Harada, N. D., Chiu, V., King, A. C., \& Stewart, A. L. (2001). An evaluation of three self-report physical activity instruments for older adults. Medicine \& Science in Sports \& Exercise, 33(6), 962-970.

Jones, M., \& Nies, M. A. (1996). The relationship of perceived benefits of and barriers to reported exercise in older African American women. Public Health Nursing, 13(2), 151-158.

Juneau, M., Rogers, F., et al. (1987). Effectiveness of self-monitored, home-based, moderate-intensity exercise training in middle-aged men and women. American Journal of Cardiology, 60(1), 66-70.

King, A. C., Castro, C., Wilcox, S., Eyler, A. A., Sallis, J. F., \& Brownson, R. C. (2000). Personal and environmental factors associated with physical inactivity among different racial-ethnic groups of U.S. middle-aged and older-aged women. Health Psychology, 19(4), 354-364.

King, A. C., Haskell, W. L., et al. (1991). Group-vs home-based exercise training in healthy older men and women. Journal of the American Medical Association, 266(11), 1535-1542.

Kinne, S., Patrick, D. L., \& Maher, E. J. (1999). Correlates of exercise maintenance among people with mobility impairments. Disability and Rehabilitation, 21(1), 15-22.

Macera, C. A., Croft, J. B., et. al. (1991). Predictors of adopting leisure-time physical activity among a biracial community cohort. American Journal of Epidemiology, 142(6), 629-635.

O'Neill, K., \& Reid, G. (1991). Perceived barriers to physical activity by older adults. Canadian Journal of Public Health, 82(6), 392-396.

Pate, R. R., Pratt, M., Blair, S. N., Haskell, W. L., Macera, C. A., Bouchard, C., et al. (1995). Physical activity and public health. A recommendation from the Centers for Disease Control and Prevention and the American College of Sports Medicine. Journal of the American Medical Association, 273(5), 402-407.

Prochaska, J. O. (1979). Systems of Psychotherapy: A Transtheoretical Analysis. Pacific Grove: BrooksCole.

Schutzer, K. A., \& Graves, B. S. (2004). Barriers and motivations to exercise in older adults. Preventive Medicine, 39(5), 1056-1061.

Stewart, A. L. (2001). Community-based physical activity programs for adults age 50 and older. Journal of Aging and Physical Activity, 9(Supplement), S71-91. 
Lattimore, D., Wilcox, S., Saunders, R. , Griffin ,S., Fallon, E., Hooker, S. \& Durstine, J.L. / Californian Journal of Health Promotion 2011, Volume 9, Issue 2, 15-28

Stewart, A. L., Mills, K. M., King, A. C., Haskell, W. L., Gillis, \& Ritter, P. L. (2001). CHAMPS Physical Activity Questionnaire for Older Adults: outcomes for interventions. Medicine \& Science in Sports \& Exercise, 33(7), 1126-1141.

Stewart, A. L., Mills, K. M., Sepsis, P. G., King, A. C., McLellan, B. Y., Roitz, K., et al. (1997). Evaluation of CHAMPS, a physical activity promotion program for older adults. Annals of Behavioral Medicine, 19(4), 353-361.

Stewart, A. L., Mills, K. M., Sepsis, P. G., King, A. C., McLellan, B. Y., Roitz, K., et al. (1997). Evaluation of CHAMPS, a physial activity promotion program for older adults. Annals of Behavioral Medicine, 19(4), 353-361.

Stewart, A. L., Verboncoeur, C. J., McLellan, B. Y., Gillis, D. E., Rush, S., Mills, K. M., et al. (2001). Physical activity outcomes of CHAMPS II: a physical activity promotion program for older adults. Journal of Gerontology, 56(8), M465-470.

Strauss, A., \& Corbin, J. (1990). Basics of Qualitative Research (1st ed.). Thousand Oaks: Sage.

Strauss, A., \& Corbin, J. (1998). Basics of Qualitative Research (2nd ed.). Thousand Oaks.

Walcott-McQuigg, J. A., \& Prohaska, T. R. (2001). Factors influencing participation of African American elders in exercise behavior. Public Health Nursing, 18(3), 194-203.

Wilcox, S., Castro, C., King, A. C., Housemann, R., \& Brownson, R. C. (2000). Determinants of leisure time physical activity in rural compared with urban older and ethnically diverse women in the United States. Journal of Epidemiology \& Community Health, 54(9), 667-672.

Wilcox, S., Dowda, M., Griffin, S. F., Rheaume, C., Ory, M. G., Leviton, L., et al. (2006). Results of the first year of active for life: translation of 2 evidence-based physical activity programs for older adults into community settings. American Journal of Public Health, 96(7), 1201-1209.

Wilcox, S., King, A. C., Brassington, G. S., \& Ahn, D. K. (1999). Physical activity preferences of middleaged and older adults: A community analysis. Journal of Aging and Physical Activity, 7(4), 386399.

Wilcox, S., Oberrecht, L., Bopp, M., Kammermann, S. K., \& McElmurray, C. T. (2005). A qualitative study of exercise in older African American and white women in rural South Carolina: perceptions, barriers, and motivations. Journal of Women \& Aging, 17(1-2), 37-53.

Wilcox, S., Richter, D. L., Henderson, K. A., Greaney, M. L., \& Ainsworth, B. E. (2002). Perceptions of physical activity and personal barriers and enablers in African-American women. Ethnicity \& Disease, 12(3), 353-362.

Zlot, A. I., Librett, J., Buckner, D., \& Schmid, T. (2006). Environmental, Transportation, Social, and Time Barriers to Physical Activity. Journal of Physical Activity and Health, 3, 15-21.

\author{
Author Information \\ Diana Lattimore, $\mathrm{PhD}$ * \\ Department of Exercise and Sport Science \\ University of San Francisco \\ Office Telephone: (415) 422-2141 \\ Fax: (415) 422-6040 \\ Email: dlattimore@usfca.edu \\ Sara Wilcox, PhD \\ Department of Exercise Science \\ University of South Carolina \\ Ruth Saunders, PhD3 \\ Department of Health Promotion and Education Behavior \\ University of South Carolina,
}


Lattimore, D., Wilcox, S., Saunders, R. , Griffin ,S., Fallon, E., Hooker, S. \& Durstine, J.L. / Californian Journal of Health Promotion 2011, Volume 9, Issue 2, 15-28

\author{
Sarah Griffin, PhD4 \\ Department of Public Health Sciences \\ Clemson University \\ Elizabeth Fallon, $\mathrm{PhD}$ \\ Department of Kinesiology \\ Kansas State University \\ Steven Hooker, $\mathrm{PhD}$ \\ Department of Exercise Science \\ University of South Carolina \\ J. Larry Durstine, $\mathrm{PhD}$ \\ Department of Exercise Science \\ University of South Carolina \\ Corresponding Author: Diana Lattimore, \\ * corresponding author
}

